Study Report 2001-04

\title{
Civilian Spouses of Soldiers: Comparison of the Results for Male and Female Spouses
}

\author{
Joanne C. Marshall-Mies \\ Swan Research, Inc.
}

\author{
Army Personnel Survey Office \\ Morris P. Peterson, Chief
}

U.S. Army Research Institute for the Behavioral and Social Sciences

5001 Eisenhower Avenue, Alexandria, Virginia 22333-5600

September 2001

Approved for public release; distribution is unlimited. 